\title{
Machiavellianism and Intimacy Attitudes in the Interpersonal Relationships
}

\author{
Chi-Fai Lo',2,3*, Eva Chor-Bing Ng2,3 \\ ${ }^{1}$ Institute of Theoretical Physics and Physics Department, The Chinese University of Hong Kong, Hong Kong, China \\ ${ }^{2}$ Department of Psychology, Sociology and Politics, Sheffield Hallam University, Sheffield, UK \\ ${ }^{3}$ Social and Human Sciences Section, SCOPE, City University of Hong Kong, Hong Kong, China \\ Email: *edcflo@gmail.com
}

How to cite this paper: Lo, C.-F., \& Ng, E. C.-B. (2019). Machiavellianism and Intimacy Attitudes in the Interpersonal Relationships. Psychology, 10, 424-433. https://doi.org/10.4236/psych.2019.104029

Received: January 22, 2019

Accepted: March 3, 2019

Published: March 6, 2019

Copyright (C) 2019 by author(s) and Scientific Research Publishing Inc. This work is licensed under the Creative Commons Attribution International License (CC BY 4.0).

http://creativecommons.org/licenses/by/4.0/

\begin{abstract}
The present study investigated the relation between Machiavellianism and intimacy attitudes in the interpersonal relationships. Male $(\mathrm{N}=46)$ and female $(\mathrm{N}=56)$ participants aged 18 to 51 years $(\mathrm{M}=31.56, \mathrm{SD}=8.00)$ were recruited to complete a questionnaire containing Mach IV Scale (Christie \& Geis, 1970) and Intimacy Attitude Scale-Revised (Amidon, Kumar, \& Treadwell, 1983). The regression analysis has revealed that Machiavellianism is a reliable predictor of the intimacy attitude of an individual, and the hypothesis that Machiavellianism is negatively correlated with positive intimacy and positively correlated with negative intimacy has been confirmed.
\end{abstract}

\section{Keywords}

Machiavellianism, Interpersonal Relationships, Mach IV Scale, Intimacy Attitude Scale-Revised (IAS-R)

\section{Introduction}

\subsection{Machiavellianism}

Today the term "Machiavellianism" has become a synonym for "cunning" because it involves interpersonal strategies that advocate self-interest, deception and manipulation (Jones \& Paulhus, 2009). Indeed, Machiavellianism, which is derived from Machiavelli's book The Prince (1532), is an interpersonally aversive personality trait based upon the political and social ideas that are portrayed in the book. Machiavellianism has come to be associated with tendencies to disdain conventional morality, lack empathy and sincerity, manipulate or exploit others in social interactions, and achieve self-interests via deception (Christie \& Geis, 1970; Vecchio \& Sussman, 1991; Fehr, Samsom, \& Paulhus, 1992; McHos- 
key, 1995; McHoskey, Worzel, \& Szyarto, 1998; Wilson, Near, \& Miller, 1998; McIlcain, 2003; Wastell \& Booth, 2003; Sherry et al., 2006; Ali \& ChamorroPremuzic, 2010; Bereczkei, Birkas, \& Kerekes, 2010; Rauthmann, 2012). Hence, individuals high in Machiavellian trait are often called "chameleons" and "wolves in sheep's clothing" in the literature (Pope, 2005; Sherry et al., 2006) for they never hesitate to break alliances, promises and rules in order to achieve their goals.

The trait of Machiavellianism is commonly measured with the Mach-IV scale (Christie \& Geis, 1970). Based upon a questionnaire of 20 items dealing with beliefs about the nature of human, values and behaviours, the Mach-IV scale is a self-report 7-point Likert-type scale which assesses three distinct themes: 1) the use of deceit in interpersonal relationships ( 9 items), 2) a cynical view of human nature ( 9 items), and 3 ) the lack of morality ( 2 items). Despite that the Mach-IV scale comprises three themes, the majority of research does not regard them as subscales (Montañés, Taracenab, \& Rodriguezc, 2004) and uses the scale as a unidimensional measure (Furnham, Richards, \& Paulhus, 2013). A basic premise of the Mach-IV scale is that high scores indicate higher endorsement of Machiavellian views and behaviour whilst low scores simply imply the opposite. The participants high in Machiavellian trait are commonly labelled as "High Machs" and those low in Machiavellian trait are referred to as "Low Machs", even though most current research tends to investigate Machiavellianism on a continuum. Previous studies revealed that High Machs were less likely to confess when they had cheated, and would try to conceal the truth (Exline et al., 1970). On the contrary, Low Machs are more open to others and liable to becoming affectively involved with them (Geis \& Moon, 1981). Hence, not all Machs are shadowy and unsavoury manipulators.

Moreover, High Machs are not only good at putting the blame upon others and low on forgiveness, but they are also deeply cynical and show a detached, controlling coolness (Christie \& Geis, 1970; Paulhus \& Williams, 2002; Lyons \& Aitken, 2010). Due to the lack of emotional attachment, High Machs prefer not to establish close intimate relationships, but these relationships, including sexual (Jonason et al., 2009; McHoskey, 2001), romantic (Ragsdale \& Brandau-Brown, 2005; Jonason \& Kavanagh, 2010) and working (Chen, 2010; Kiazad et al., 2010) relationships, do provide them with opportunities for emotional manipulation, such as coercion and pleasure induction, and subsequent reward (Lyons \& Aitken, 2010; Brewer, Abell, \& Lyons, 2014). All in all, increasing attention has been drawn towards the study of Machiavellianism in recent years owing to its prominence in subclinical populations and influence on psychological adjustment (McHoskey, 1999; Martin et al., 2012).

\subsection{Machiavellianism and Interpersonal Relationships}

Even though High Machs place little importance on engaging a close relationship, it happens, especially when the relationship can bring benefits to them (Mandal, 2008). As suggested by Christie \& Geis (1970), High Machs differ from 
Low Machs primarily by their lack of emotional attachment. The emotionally detached interpersonal orientation is in fact an essential factor of Machiavellianism; High Machs and Low Machs are described by the terms "cool syndrome" and "soft touch", respectively (Christie \& Geis, 1970). Given High Machs' lack of emotional attachment, it is quite natural that they exhibit deficits in empathy (Wastell \& Booth, 2003; Jones \& Paulhus, 2009). Numerous studies have found that Machiavellianism bears a negative correlation with empathy (Watson, Biderman, \& Sawrie, 1994; Wastell \& Booth, 2003; Austin et al., 2007). Such empathy deficits may not only offer High Machs an advantage in their ability to manipulate or deceive others in order to achieve their own goals, but they may also harm their social relationships. Accordingly, it is not easy for High Machs to get involved in close relationships; their interpersonal relations are associated with hostile behaviours as well as characterized by a great deal of distrust, disrespect and lack of loyalty.

Owing to their difficulties with intimacy and reluctance to establish close interpersonal relationships, High Machs tend to involve in short-term relationships of a sexual nature rather than long-term committed relationships (Brewer \& Abell, 2017). This is consistent with the previous research findings which have demonstrated that Machiavellianism is negatively related to the intimate relationship dimensions such as intimacy and commitment (Sternberg, 1986, 1988; Ali \& Chamorro-Premuzic, 2010). Besides, High Machs not only often report lower levels of relationship satisfaction, but they are also characterized by promiscuity, anxiety and hostility (Egan \& Agnus, 2004; Ali \& Chamorro-Premuzic, 2010; Hyla, 2012; Brewer \& Abell, 2017). In a recent study of the relationship between Machiavellianism and adult attachment in both general interpersonal relationships and close relationships, Ináncsi, Láng, \& Bereczkei (2015) have also found that while Low Machs are securely attached, High Machs show a dismissing-avoidant attachment style in their interpersonal relationships, and that avoidance is further accompanied by some characteristics of attachment anxiety in close relationships.

Nevertheless, there is still little known about the intimacy attitudes of the individuals with more pronounced Machiavellian trait in the interpersonal relationships. To help fill in the aforementioned gap in the psychological literature, this study attempts to investigate the intimacy attitudes of these individuals in their interpersonal relationships by means of the Intimacy Attitude Scale-Revised (IAS-R) (Amidon, Kumar, \& Treadwell, 1983). The IAS-R was designed to measure constructs of positive intimacy and negative intimacy within the interpersonal relationships. Positive intimacy is defined as the degree to which a person wants to share feelings, ideas and experiences in the interpersonal relationships. On the other hand, negative intimacy is the degree to which a person is concerned with domination, conflict, criticism, freedom, distrust and powerlessness. Amidon, Kumar, \& Treadwell (1983) reported that people with high scores on the IAS-R tended to engage in more intimate behaviours, to self-disclose more to others, to feel in control of their fate, to be more active, and to ex- 
perience less alienation from friends, family and self. Undoubtedly, this study will facilitate a better understanding of High Machs' views on the interpersonal relationships and the manner in which the Machiavellian trait may function in these relationships.

\subsection{Objectives and Hypotheses}

The main purpose of this study is to investigate the intimacy attitudes of the individuals with more pronounced Machiavellian trait in the interpersonal relationships. Particularly, given that High Machs show a dismissing-avoidant attachment style in their interpersonal relationships (Ináncsi, Láng, \& Bereczkei, 2015), we formulate the following hypotheses:

a) Machiavellianism is negatively correlated with the score on the IAS-R.

b) Machiavellianism is a significant predictor of the score on the IAS-R.

c) Machiavellianism is positively correlated with negative intimacy and negatively correlated with positive intimacy.

\section{Methodology}

\subsection{Participants}

A total of 166 individuals were recruited to participate in this study from social network sites by convenience sampling but only 102 participants (age 18 to 51, $\mathrm{M}=31.56, \mathrm{SD}=8.00)$ completed the full set of online questionnaire. The sample consisted of 46 men (age 18 to $50, \mathrm{M}=33.09, \mathrm{SD}=8.46$ ) and 56 women (age 18 to $51, \mathrm{M}=30.30, \mathrm{SD}=7.43$ ).

\subsection{Measures}

Two instruments were administered to collect the research data. The first instrument is the Mach-IV Scale developed by Christie \& Geis (1970) and the second one is the Intimacy Attitude Scale-Revised constructed by Amidon, Kumar, \& Treadwell (1983).

\subsubsection{Mach IV Scale}

The Mach IV Scale (Christie \& Geis, 1970) contains 20 items rated on a seven point Likert scale $(1=$ strongly disagree to $7=$ strongly agree $)$ and is used to evaluate agreement with Machiavellian beliefs in interactions with others, morality and cynicism. The twenty items are divided into three categories, namely 9 items on the use of tactics in interpersonal relationships, 9 items on cynical views of human nature and 2 items on lacking of morality. As ten items of the scale show avoidance of Machiavellian attitude instead of acceptance, they have been reverse scored. The total score ranges from 20 to 140. Using the cut-off point of 80 , people scoring above 80 are identified as High Machs whereas those scoring 80 or below are known as Low Machs. This scale has demonstrated high internal consistency as well as acceptable reliability and validity in various previous studies (Fehr, Samsom, \& Paulhus, 1992). Example items include "Honesty is the best policy in all cases.", "There is no excuse for lying to someone else.", 
"Never tell anyone the real reason you did something unless it is useful to do so", and "Anyone who completely trusts anyone else is asking for trouble." Besides, the name "Barnum" in Item 17 has been replaced by "people" in order that the local people in Hong Kong can understand the question better.

\subsubsection{Intimacy Attitude Scale-Revised}

The IAS-R (Amidon, Kumar, \& Treadwell, 1983) is the revised form of the intimate attitude scale that was originally created by Edmund Amidon in 1978. It contains 50 items rated on a five point Likert scale $(1=$ strongly disagree to $5=$ strongly agree) and is used to assess attitudes of closeness, intimacy and trust that people have toward others and relationships with others. Of the 50 items, 26 items are negatively worded and need to be reverse scored. In other words, there are 24 items measuring positive intimacy whilst the remaining 26 items measure negative intimacy. Both structural validity and content validity of the scale were confirmed by correlating the IAS-R with several intimacy scales and approved by a number of professional editors. Example items include "I like to share my feelings with others.", "I want to be sure that I am in good control of myself before I attempt to become intimate with another person.", "I am concerned with rejection in my expression of feelings to others.", and "I try to trust and be close to others." Since sexual revealing is not commonly shared or disclosed among interpersonal relationships, the 3 items concerning body and sexual revealing (e.g. "Undressing with members of a group increases my feelings of intimacy.") were excluded in this study. Thus, the total score ranges from 47 to 235 .

\subsection{Procedures}

Participants were invited to participate in a web-based online questionnaire comprising the 20 items of Mach IV Scale and the 47 items of the IAS-R. All the required briefing and de-briefing information were provided with the questionnaire. Since the participants were over the age of 18 , no parental or guardian consent was needed.

\section{Results}

\subsection{Descriptive Statistics}

The reliability of the Mach IV Scale and IAS-R was analyzed using the SPSS. After excluding those items that have negative corrected item-total correlations (2 items from the Mach IV Scale and 5 items from the IAS-R), the Cronbach's alpha value of the Mach IV Scale is acceptable $(\alpha=0.644)$ whilst the IAS-R exhibits a very strong Cronbach's alpha value $(\alpha=0.821)$. Before performing the correlation analysis, normality checks for the two scales were conducted. The following descriptive statistics data were obtained: Mach IV Scale $(M=64.56$, $\mathrm{SD}=10.03$, Skewness $=-0.023$ with $\mathrm{SE}=0.239$, Kurtosis $=-0.026$ with $\mathrm{SE}=$ $0.474)$ and IAS-R $(\mathrm{M}=138.83, \mathrm{SD}=14.20$, Skewness $=-0.013$ with $\mathrm{SE}=0.239$, Kurtosis $=0.216$ with $\mathrm{SE}=0.474)$. It is clear that the skewness and kurtosis data all seem to imply normal distributions. The normality was also confirmed by the 
Shapiro-Wilk test results: Mach IV Scale $(\mathrm{S}-\mathrm{W}=0.994, \mathrm{df}=102, p=0.941)$ and IAS-R $(S-W=0.988, \mathrm{df}=102, p=0.508)$. In addition, other results like the Q-Q plots, box plots and histograms with normal distribution curves were scrutinized such that the parametric assumptions of the two scales could be checked.

Moreover, similar tests and analyses were applied to the 19 items on positive intimacy and 23 items on negative intimacy. The numerical results can be summarized as follows:

a) Positive intimacy: Cronbach's alpha value $\alpha=.825 ;(M=70.18, S D=8.38$, Skewness $=-0.265$ with $\mathrm{SE}=0.239$, Kurtosis $=-0.075$ with $\mathrm{SE}=0.474) ;(\mathrm{S}-\mathrm{W}=$ $0.988, \mathrm{df}=102, p=0.525)$.

b) Negative intimacy: Cronbach's alpha value $\alpha=0.841 ;(\mathrm{M}=69.34, \mathrm{SD}=$ 11.25, Skewness $=-0.158$ with $\mathrm{SE}=0.239$, Kurtosis $=0.245$ with $\mathrm{SE}=0.474$ ); $(\mathrm{S}-\mathrm{W}=0.989, \mathrm{df}=102, p=0.601)$.

It should be noted that here no reverse scoring is applied to the 23 items on negative intimacy.

\subsection{Hypothesis Testing}

Scatter plots with lines of best fit were examined to check for the linear assumptions involving the Pearson correlations. Results of the scatter plots indicate that all the correlations are linear. As such, the Pearson correlation coefficient between the two scales was computed using the SPSS as $(\mathrm{r}=-0.361, p<0.001, \mathrm{n}=$ 102, 2-tailed). Accordingly, the hypothesis that the Mach IV Scale score is negatively correlated with the IAS-R score is confirmed. Likewise, linear regression was applied to determine the linear relation between the two scales. A significant regression equation was found $(\mathrm{F}(1,100)=14.941, p<0.001)$, with an adjusted $R^{2}$ of 0.121 ; participant's predicted IAS-R score is equal to $171.766-0.510 \times$ (Mach IV Scale score). The regression analysis indicates that the Mach IV Scale score $(\beta=-0.361, p<0.001)$ is a significant predictor of the IAS-R score. This is consistent with the results of correlation analysis.

Furthermore, similar correlation analysis among the Mach IV Scale score, the positive intimacy score and the negative intimacy score was conducted to yield the Pearson correlation coefficient between: a) Mach IV Scale and positive intimacy as ( $\mathrm{r}=-0.225, p=0.023, \mathrm{n}=102,2$-tailed), b) Mach IV Scale and negative intimacy as $(\mathrm{r}=0.287, p=0.003, \mathrm{n}=102,2$-tailed $)$, and $\mathrm{c}$ ) positive intimacy and negative intimacy as $(\mathrm{r}=-0.025, p=0.803, \mathrm{n}=102,2$-tailed $)$. Obviously, these numerical results confirm the hypothesis that Machiavellianism is negatively correlated with positive intimacy and positively correlated with negative intimacy.

\section{Discussion}

The main purpose of this study is to investigate the relation between Machiavellianism and intimacy attitudes in the interpersonal relationships. Findings of the correlation analysis show that individuals with more pronounced Machiavellian 
trait are characterized by lower IAS-R scores. In other words, Machiavellianism is negatively correlated with the score on the IAS-R. Regression analysis suggests that Machiavellianism is a significant predictor of the score on the IAS-R, too. These results comply with previous studies that Machiavellianism is negatively related to the intimate relationship dimensions of Sternberg, namely intimacy and commitment (Sternberg, 1986, 1988; Ali \& Chamorro-Premuzic, 2010) as well as that High Machs show a dismissing-avoidant attachment style in their interpersonal relationships (Ináncsi, Láng, \& Bereczkei, 2015). Moreover, our correlation analysis has demonstrated that Machiavellianism is positively correlated with negative intimacy and negatively correlated with positive intimacy. These findings reinforce the conventional picture that High Machs place little importance on engaging a close relationship (Christie \& Geis, 1970; Ali \& Chamorro-Premuzic, 2010) and exhibit deficits in empathy (Wastell \& Booth, 2003; Jones \& Paulhus, 2009). Nevertheless, it should be noted that perhaps due to the small sample size our analysis of the gender differences fails to yield any statistically significant finding.

\section{Conclusion}

In conclusion, Machiavellianism is found in the current study to be a reliable predictor of the intimacy attitude of an individual, and this result coincides with those of correlation analysis: the Mach IV Scale negatively correlates with the IAS-R as well as Machiavellianism negatively (positively) correlates with positive (negative) intimacy. This study represents only a small contribution in the field of Machiavellianism and intimate relationships, and its findings may help shed light upon the direction of future research. For instance, the intimacy attitude of an individual may comprise a number of major components rather than the two constructs of positive intimacy and negative intimacy, and thus a multi-dimensional analysis of the relation between Machiavellianism and intimacy attitudes in the interpersonal relationships is highly desirable.

There are several major limitations in the present study. First, the sample in this study was obtained by convenience sampling and might not represent the whole population. Second, the conclusions of the current study are of course restricted by a reliance on self-reported data which are inevitably subject to social desirability, random responding, biased interpretation and recall accuracy. Third, as interpersonal relationships are dyadic, the perception of both members of the dyad is important for establishing the processes involved in developing intimacy and closeness. A dyadic approach thus provides valuable opportunities for future research. Lastly, the correlational questionnaire design does not allow us to infer causality, so longitudinal research monitoring the development and maintenance of interpersonal relationship dyads is recommended.

\section{Acknowledgements}

The authors would like to thank Dr. Sue Jamison-Powell and Dr. Jonathan 
Yeung for their useful comments and suggestions.

\section{Conflicts of Interest}

The authors declare no conflicts of interest regarding the publication of this paper.

\section{References}

Ali, F., \& Chamorro-Premuzic, T. (2010). The Dark Side of Love and Life Satisfaction: Association with Intimate Relationship, Psychology and Machiavellianism. Personality and Individual Differences, 48, 228-233. https://doi.org/10.1016/j.paid.2009.10.016

Amidon, E., Kumar, V. K., \& Treadwell, T. (1983). Measurement of Intimacy Attitudes: The Intimacy Attitude Scale-Revised. Journal of Personality Assessment, 47, 635-639. https://doi.org/10.1207/s15327752jpa4706_9

Austin, E. J., Farrelly, D., Black, C., \& Moore, H. (2007). Emotional Intelligence, Machiavellianism and Emotional Manipulation: Does EI Have a Dark Side? Personality and Individual Differences, 43, 179-189. https://doi.org/10.1016/j.paid.2006.11.019

Bereczkei, T., Birkas, B., \& Kerekes, Z. (2010). The Presence of Others, Prosocial Traits, Machiavellianism: A Personality $\times$ Situation Approach. Social Psychology, 41, 238-245. https://doi.org/10.1027/1864-9335/a000032

Brewer, G., \& Abell, L. (2017). Machiavellianism and Romantic Relationship Dissolution. Personality and Individual Differences, 18, 226-230. https://doi.org/10.1016/j.paid.2016.11.001

Brewer, G., Abell, L., \& Lyons, M. (2014). Machiavellianism, Competition and Self-Disclosure in Friendship. Individual Differences Research, 12, 1-7.

Chen, S. Y. (2010). Relations of Machiavellianism with Emotional Blackmail Orientation of Salespeople. Procedia-Social and Behavioral Sciences, 5, 294-298. https://doi.org/10.1016/j.sbspro.2010.07.091

Christie, \& Geis (1970). Studies in Machiavellianism. New York, NY: Academic Press.

Egan, V., \& Agnus, S. (2004). Is Social Dominance a Sex-Specific Strategy for Infidelity? Personality and Individual Differences, 36, 575-586. https://doi.org/10.1016/S0191-8869(03)00116-8

Exline, R., Thiabaut, J., Hickey, C., \& Gumpert, P. (1970). Visual Interaction in Relation to Machiavellianism and an Unethical Act. In Christie, \& Geis (Eds.), Studies in Machiavellianism (pp. 53-75). New York: Academic Press. https://doi.org/10.1016/B978-0-12-174450-2.50009-9

Fehr, B., Samsom, E., \& Paulhus, D. L. (1992). The Construct of Machiavellianism: Twenty Years Later. In C. D. Spielberger, \& J. N. Butcher (Eds.), Advances in Personality Assessment (pp. 77-116). Hillsdale, NJ: Erlbaum.

Furnham, A., Richards, S. C., \& Paulhus, D. L. (2013). The Dark Triad of Personality: A 10 Year Review. Social and Personality Psychology Compass, 7, 199-216. https://doi.org/10.1111/spc3.12018

Geis, F. L., \& Moon, T. H. (1981). Machiavellianism and Deception. Journal of Personality and Social Psychology, 41, 766-775. https://doi.org/10.1037/0022-3514.41.4.766

Hyla, M. (2012). Machiavellianism, Relationship Satisfaction, and the Use of Influence Tactics in a Close Relationship. International Masaryk Conference, 2764-2773.

Ináncsi, T., Láng, A., \& Bereczkei, T. (2015). Machiavellianism and Adult Attachment in General Interpersonal Relationships and Close Relationships. Europe's Journal of Psy- 
chology, 11, 139-154. https://doi.org/10.5964/ejop.v11i1.801

Jonason, P. K., \& Kavanagh, P. (2010). The Dark Side of Love: Love Styles and the Dark Triad. Personality and Individual Differences, 49, 606-610. https://doi.org/10.1016/j.paid.2010.05.030

Jonason, P. K., Li, N. P., Webster, G. D., \& Schmitt, D. P. (2009). The Dark Triad: Facilitating a Short-Term Mating Strategy in Men. European Journal of Psychology, 23, 5-18. https://doi.org/10.1002/per.698

Jones, D. N., \& Paulhus, D. L. (2009). Machiavellianism. In M. R. Leary, \& R. H. Hoyle (Eds.), Individual Differences in Social Behaviour (pp. 93-109). New York: Guilford.

Kiazad, K., Restubog, S. L. D., Zagenczyk, T. J., Kiewitz, C., \& Tang, R. L. (2010). In Pursuit of Power: The Role of Authoritarian Leadership in the Relationship between Supervisors' Machiavellianism and Subordinates' Perceptions of Abusive Supervisory Behaviour. Journal of Research in Personality, 44, 512-519.

https://doi.org/10.1016/j.jrp.2010.06.004

Lyons, M., \& Aiken, S. (2010). Machiavellian Friends? The Role of Machiavellianism in Friendship Formation and Maintenance. Journal of Social, Evolutionary and Cultural Psychology, 4, 194-202. https://doi.org/10.1037/h0099290

Mandal, E. (2008). Love, Authority and Manipulation in Close Relationships. Warszawa: Wydawnictwo Naukowe PWN.

Martin, R. A., Lastuk, J. M., Jeffery, J., Vernon, P. A., \& Veselka, L. (2012). Relationships between Dark Triad and Humor Styles: A Replication and Extension. Personality and Individual Differences, 52, 178-182. https://doi.org/10.1016/j.paid.2011.10.010

McHoskey, J. W. (1995). Narcissism and Machiavellianism. Psychological Reports, 77, 753-759. https://doi.org/10.2466/pr0.1995.77.3.755

McHoskey, J. W. (1999). Machiavellianism, Intrinsic versus Extrinsic Goals, and Social Interest: A Self-Determination Theory Analysis. Motivation and Emotion, 23, 267-283. https://doi.org/10.1023/A:1021338809469

McHoskey, J. W. (2001). Machiavellianism and Sexuality: On the Moderating Role of Biological Sex. Personality and Individual Differences, 31, 779-789.

https://doi.org/10.1016/S0191-8869(00)00180-X

McHoskey, J. W., Worzel, W., \& Szyarto, C. (1998). Machiavellianism and Psychopathy. Journal of Personality and Social Psychology, 74, 192-210. https://doi.org/10.1037/0022-3514.74.1.192

McIlcain, D. (2003). Bypassing Empathy: A Machiavellian Theory of Mind and Sneaky Power. In B. Repacholi, \& V. Slaughter (Eds.), Individual Differences in Theory of Mind: Implications for Typical and Atypical Development (pp. 39-67). Hove: Psychology Press.

Montañés, R., Taracenab, L., \& Rodriguezc, M. (2004). Assessment of Machiavellian Intelligence in Antisocial Disorder with the Mach-IV Scale. Actas Española de Psiquiatr, 32, 65-70.

Paulhus, D. L., \& Williams, K. M. (2002). The Dark Triad of Personality: Narcissism, Machiavellianism and Psychopathy. Journal of Research in Personality, 36, 556-563. https://doi.org/10.1016/S0092-6566(02)00505-6

Pope, K. R. (2005). Measuring the Ethical Propensities of Accounting Students: MACH IV versus DIT. Journal of Academic Ethics, 3, 89-111. https://doi.org/10.1007/s10805-005-9000-2

Ragsdale, J. D., \& Brandau-Brown, F. E. (2005). Individual Differences in the Use of Relational Maintenance Strategies in Marriage. The Journal of Family Communication, 5, 
61-75. https://doi.org/10.1207/s15327698jff0501_4

Rauthmann, J. F. (2012). Towards Multifaceted Machiavellianism: Content, Factorial, and Construct Validity of a German Machiavellianism Scale. Personality and Individual Differences, 52, 345-351. https://doi.org/10.1016/j.paid.2011.10.038

Sherry, S. B., Hewitt, P. L., Besser, A., Flett, G. L., \& Klein, C. (2006). Machiavellianism, Trait Perfectionism and Perfectionistic Self-Presentation. Personality and Individual Differences, 40, 829-839. https://doi.org/10.1016/j.paid.2005.09.010

Sternberg, R. J. (1986). A Triangular Theory of Love. Psychological Review, 93, 119-135. https://doi.org/10.1037/0033-295X.93.2.119

Sternberg, R. J. (1988). Triangulating Love. In R. J. Sternberg, \& M. L. Barnes (Eds.), The Psychology of Love (pp. 119-138). New Haven, CF: Yale University Press.

Vecchio, R. P., \& Sussman, M. (1991). Choice of Influence Tactics: Individual and Organizational Determinants. Journal of Organizational Behavior, 12, 73-80. https://doi.org/10.1002/job.4030120107

Wastell, C., \& Booth, A. (2003). Machiavellianism: An Alexithymic Perspective. Journal of Social and Clinical Psychology, 22, 730-744. https://doi.org/10.1521/jscp.22.6.730.22931

Watson, P. J., Biderman, M. D., \& Sawrie, S. M. (1994). Empathy, Sex Role Orientation and Narcissism. Sex Roles, 30, 701-723. https://doi.org/10.1007/BF01544671

Wilson, D. S., Near, D. C., \& Miller, R. R. (1998). Individual Differences in Machiavellianism as a Mix Cooperative and Exploitative Strategies. Evolution and Human Behavior, 19, 203-212. https://doi.org/10.1016/S1090-5138(98)00011-7 